\title{
Targeting lung attacks
}

\section{J Mark FitzGerald}

Acute exacerbations of asthma and chronic obstructive lung disease (COPD) are significant burdens on the health care system. ${ }^{12}$ The economic burden is particularly high with both types of exacerbations. Unfortunately the management of these common occurrences is often haphazard and fragmented. The gaps in care relate both to the management of the specific episode in question ${ }^{3}$ and to the risk stratification of patients subsequent to the event. ${ }^{4}$ This lack of current and ongoing optimal care is disappointing, especially given the documented poor prognostic factors associated with these events. Patients hospitalised with acute asthma, and especially episodes of near fatal asthma, are associated with significantly increased future risks of intubation. ${ }^{5}$ In the case of COPD the outcomes are even more dramatic; in-hospital mortality for an acute exacerbation of COPD is at least $10 \%$ and 1-year mortality, posthospitalisation, approaches $25 \%$. In addition to these immediate increased risks associated with exacerbations there is also a significant decline in lung function associated with both types of exacerbations. ${ }^{67}$ Given these data, the response of the health care system to these events is disappointing. ${ }^{7}$ This response is quite different from what occurs with a 'heart attack'. In the case of an acute myocardial infarction initial management is much more aggressive, risk stratification is routine and patients are usually discharged on a medication bundle. In addition standard of care involves patients being enrolled in well-funded cardiac rehabilitation programmes. Similar comparisons have been drawn with the previously used term of a stroke which has in many settings been replaced with the term 'brain attack'.

Part of the challenge involves the health care provider as well as patient perception of the seriousness of the primary event. Patients do not identify with the term 'exacerbation'. In addition, a common perception, especially among patients

Institute for Heart and Lung Health, Vancouver General Hospital and the University of British Columbia, Canada

Correspondence to J Mark FitzGerald, The Lung Centre, 2775 Laurel Street, Vancouver, BC V5Z 1M9, Canada; markf@interchange.ubc.ca with COPD, is that the primary cause of their current health status is the patient's history of smoking, which leads to stigma and a nihilistic attitude. The age of a patient with COPD may, on average, be older than that of a patient presenting with an acute ischaemic event and therefore the implications may somehow be seen to be less serious. Historically there was a therapeutic nihilism with both conditions, especially COPD. We now have multiple therapeutic options, with a clear and strong evidence base for the use of 'triple therapy' (a combination of a long-acting bronchodilator, an inhaled corticosteroid and a long-acting anticholinergic) in patients with a history of acute exacerbations of COPD (AECOPD). ${ }^{8}$ In addition we now have evidence for the use of pulmonary rehabilitation and, of more importance in the current discussion, for the use of rehabilitation immediately after AECOPD. ${ }^{9}$ The therapeutic role for roflumilast in the current setting is unclear but, given that it brings a unique mode of action unlike any of the current recommended treatments, it may well have a role as add-on therapy in these high risk hospitalised patients. ${ }^{10}$ Again, using cardiology as an example, in that domain we would now be embarking on a mega trial looking at the additional add-on benefit of this therapy to the current standard of care. With the emerging evidence for the potential role of statins $^{11}$ and $\beta$-blockers ${ }^{12}$ in patients with COPD, a care bundle to rival the postacute myocardial infarction standard of care may well emerge.

Although the model outlined above for COPD may not immediately appear relevant to asthma, we know that many patients presenting to the Emergency Department, ${ }^{13}$ and in many cases hospitalised, are on suboptimal outpatient treatment. At the most extreme, this may only involve a short-acting bronchodilator medication. Available incremental treatments in this setting would include the addition of inhaled corticosteroids and a long-acting bronchodilator. Additional therapeutic options in this setting will include a leukotriene modifier and, in a select population of patients, a monoclonal antibody, omalazumab. ${ }^{14}$ With the likely future availability of other biologicals, for both asthma and COPD, risk stratification and optimal use of current treatments prior to the introduction of these new therapies, which will probably be expensive, will be even more crucial.

Common to both conditions will be the opportunity to provide smoking cessation interventions including both pharmacological and behavioural options. Probably the most underutilised part of a potential bundle of care for 'lung attacks' is the use of a structured educational programme. In asthma there is abundant evidence that education, integrating a written action plan, leads to better outcomes, most notably a reduction in future Emergency Department visits as well as hospitalisations. ${ }^{15}$ In addition, a similar intervention with the use of case managers has been shown to be an effective and costeffective intervention in COPD. ${ }^{16}$

This conceptual model of care with a bundle of interventions is well documented in the cardiac literature, but there is additional evidence for this approach in preventing nosocomial pneumonia. ${ }^{17} \mathrm{~A}$ similar systems approach involves the use of check lists, by physicians and health care providers, which has been shown to be very effective in anaesthesia and more recently in reducing perioperative mortality. ${ }^{18}$ It would seem sensible to define an optimal, evidence-based bundle of care for patients discharged from the Emergency Department or from an inpatient admission following a 'lung attack', and to develop an optimal standard of care which could be structured in a 'list format'. This should not be seen as a simple 'cook book' approach to care but will need to be developed in the context of the individual patient. Issues around cost and availability of medications on formulary and also such important issues as health literacy and ethnicity will also need to be taken into account. ${ }^{19}$ Although in this perspective we have focused on exacerbations in two common conditions and therefore show their high economic and social burden on the health care system, it is also important to realise that there are similar significant impacts on the disease trajectories in two other less common conditions: cystic fibrosis ${ }^{20}$ and interstitial pulmonary fibrosis. ${ }^{21}$ Further research into the systemic inflammatory response seen in these conditions will probably show common pathways that may be amenable to a systemic modulation of inflammation. As noted above, there is emerging evidence that statins may provide such a prototype at least for asthma and COPD. 
In conclusion, there is convincing evidence that current management strategies for acute asthma and AECOPD within and subsequent to discharge from hospital are suboptimal. The reasons for this are probably multifactorial. In this perspective we hypothesise that we need to identify a term that will resonate with patients and also care providers to investigate other models of care that look at multiple interventions for patients who have been appropriately risk stratified. We suggest that the term 'lung attack' may resonate more with patients and the broader community. In many cases we already have the evidence base for such bundles, but with the broadening of therapeutic options, much like in the cardiology literature, there will be a need for large mega trials to answer such questions. With the recognition of asthma and COPD as major chronic diseases in emerging economies, the potential to perform such large trials in these settings, in a cost-effective and timely fashion, will also be convenient in countries such as India and China. These will be pragmatic locations for these studies, but they will also be appropriate as these countries will probably be the location of an emerging epidemic of respiratory, as well as other chronic diseases. We also propose that a systems approach to the use of such bundles, with simple checklists, will also probably improve outcomes.

Competing interests Advisory Boards and Speakers Bureau: GSK, AZ, Merck $>\$ 10,000$. BI, Novartis, Nycomed $<\$ 10,000$. Research funding paid directly to UBC: CIHR GSK, BI, Medimmune, Wyeth, Pharmaxis, Novartis, AllerGen NCE, Genetech, Topigen $>\$ 10,000$. Member of the GINA Executive and Chair of GINA
Science Committee. Member of CTS Asthma committee.

Provenance and peer review Not commissioned; not externally peer reviewed.

Published Online First 11 March 2011

Thorax 2011;66:365-366.

doi:10.1136/thx.2010.156760

\section{REFERENCES}

1. Bahadori K, Doyle-Waters MM, Marra C, et al. Economic burden of asthma: a systematic review. BMC Pulm Med 2009;9:24.

2. Mittmann N, Kuramoto L, Seung SJ, et al. The cost of moderate and severe COPD exacerbations to the Canadian health care system. Resp Med 2008;102:413-21.

3. Burney P, Potts J, Aït-Khaled N, et al. A multinational study of treatment failures in asthma management. Int J Tuberc Lung Dis 2008;12:13-18.

4. Sharma G, Kuo YF, Freeman JL, et al. Outpatient follow-up visit and 30-day emergency department visit and readmission in patients hospitalized for chronic obstructive pulmonary disease. Arch Intern Med 2010;170:1664-70.

5. Turner MO, Crump S, Vedal S, et al. Risk factors for near fatal asthma: results from a prospective case control study. Am J Respir Crit Care Med 1998:157:1804-9

6. Bai TR, Vonk JM, Postma DS, et al. Severe exacerbations predict excess lung function decline in asthma. Eur Respir J 2007;30:452-6.

7. Donaldson GC, Wedzicha JA. COPD exacerbations: epidemiology. Thorax 2006;61:164-8.

8. Aaron SD, Vandemheen $\mathrm{KL}$, Fergusson $\mathrm{D}$, et al; for the Canadian Thoracic Society/Canadian Respiratory Clinical Research Consortium. Tiotropium in combination with placebo, salmeterol, or fluticasone/ salmeterol for chronic obstructive pulmonary disease: a randomized trial. Ann Intern Med 2007; 146:545-55.

9. Seymour JM, Moore L, Jolley CJ, et al. Chronic obstructive pulmonary disease: outpatient pulmonary rehabilitation following acute exacerbations of COPD. Thorax 2010;65:423-8.

10. Fabbri LM, Calverley PM, Izquierdo-Alonso JL, et al. Roflumilast in moderate-to-severe chronic obstructive pulmonary disease treated with longacting bronchodilators: two randomized clinical trials. Lancet 2009;374:695-703.

11. Janda S, Park K, FitzGerald JM et al. Statins in COPD: a systematic review. Chest 2009;136:734-43.

12. Rutten FH, Zuithoff NP, Hak E, et al. $\beta$-Blockers may reduce mortality and risk of exacerbations in patients with chronic obstructive pulmonary disease. Arch Intern Med 2010;170:880-7.

13. Fitzgerald JM, O'Byrne PM, McFetridge JT, et al. Pulmonary function testing in the emergency department and medications prescribed at discharge: results of the Multinational Acute asthma Management, Burden, and Outcomes (MAMBO) study. Prim Care Respir J 2010;19:155-62.

14. Bateman ED, Hurd SS, Barnes PJ, et al. Global strategy for asthma management and prevention: GINA executive summary. Eur Respir J 2008;31:143-78.

15. Gibson PG, Powell H, Wilson A, et al. Self management education and regular practitioner review for adults with asthma. Cochrane Database Syst Rev 2003;(1)CD001117.

16. Bourbeau J, Julien M, Maltais F, et al; for the Chronic Obstructive Pulmonary Disease axis of the Respiratory Network Fonds de la Recherche en Santé du Québec. Reduction of hospital utilization in patients with chronic obstructive pulmonary disease. A disease-specific self-management intervention. Arch Intern Med 2003;163:585-91.

17. Resar R, Pronovost P, Haraden C, et al. Using a bundle approach to improve ventilator care processes and reduce ventilator-associated pneumonia. Jt Comm J Qual Patient Saf 2005;31:243-8.

18. Haynes AB, Weiser TG, Berry WR, et al; for the Safe Surgery Saves Lives Study Group. A surgical safety checklist to reduce morbidity and mortality in a global population. N Engl J Med 2009;360:491-9.

19. Poureslami IM, Rootman I, Balka $\mathrm{E}$, et al. A systematic review of asthma and health literacy: a cultural-ethnic perspective in Canada. MedGenMed 2007;9:40.

20. Goss CH, Burns JL. Exacerbations in cystic fibrosis 1: epidemiology and pathogenesis. Thorax 2007:62:360-7

21. Collard HR, Moore BB, Flaherty KR, et al; the Idiopathic Pulmonary Fibrosis Clinical Research Network Investigators. Acute exacerbations of idiopathic pulmonary fibrosis. Am J Respir Crit Care Med 2007:176:636-43.

\section{Thorax alerts}

Sign up for our electronic table of contents alerts and you will never miss new issues of Thorax when published online. Stay ahead and up to date by visiting thorax.bmj.com. 